\title{
Meta-Art History: Introduction to a Narratological Study of Art History
}

\author{
Lian Duan \\ Senior Lecturer and Coordinator in Chinese, Department of Classics, \\ Modern Languages, and Linguistics, Concordia University, Montreal, \\ Quebec, Canada \\ lian.duan@concordia.ca
}

\begin{abstract}
This article outlines a narratological study of art history, discussing how to tell the story of art while telling the story. With this twofold purpose in mind, the author in this article draws the grande ligne of a narrative model on the one hand and proposes a historical argument about modern Chinese art on the other. The former aims at breaking down the boundary between intrinsic and extrinsic studies of art history, whereas the latter aims at proposing a main thesis about modern Chinese art. For the main thesis, the author argues that the development of Chinese art in the twentieth and the early twenty-first centuries is primarily determined by the interaction between the influence of Western art and the Chinese responses to the influence, and the response is driven by the Chinese anxiety of cultural identity over the last one hundred years. Although the topic of this article is centralized around modern Chinese art, the theorization of the methodological approach is to generalize the narrative model for the study of not only art history but also visual culture, critical theory, and relevant disciplines in the humanities.
\end{abstract}

\section{Keywords}

narrative - meta-art history - influence - response - identity

Art history studies art in a broad sense and narrates the development of art in a narrow sense. This article concerns the development of Chinese art in the twentieth and the early twenty-first centuries and offers a narratological 
discussion of how to write and rewrite art history. Focusing on Western influence on Chinese art and Chinese responses to the influence, this article argues that both influence and responses have together conditioned and shaped the development of Chinese art at every historical turning point in modern times. Although the topic is modern Chinese art, the critical notions developed in this study can be theorized as a narratological approach to art history in general.

Subject and Approach

Western influence on modern Chinese art unfolds in three historical periods throughout the past century, with unique cultural traits: the first wave of the influence reached China directly in the early first half of the twentieth century; the second wave reached China indirectly, through Soviet art, in the early second half of the twentieth century; and the third wave prevailed in China directly again in the last two decades of the same century. There are many venues for Western influence to reach China; I summarize four: exhibitions of Western art in China, Western professionals teaching art and art theory in China, Chinese students studying art and art theory in the West, and translating Western art and art theory into Chinese.

The Chinese response to Western influence is complex, involving Chinese artists' search for cultural identity through artistic practice. I will explore the response in three dimensions. The first is a general observation: faced with direct Western influence in the first half of the twentieth century, modern Chinese art split into two mainstreams, Western-style art and traditional-style art. Each mainstream was itself split into two, the realist art and modernist art in the former and the conservative art and innovative art in the latter.

The second dimension is a more specific historical elaboration of the Chinese response of four generations throughout modern times. The above two mainstreams and two sub-splits are showcased in the art of the firstgeneration artists in the first half of the past century; the indirect influence via Soviet art is showcased by the adoption of the Socialist Realist art in the works of the second-generation artists from the early 1950s to the late 197os; the third-generation artists embraced Western Realist art in the 1980s, and the fourth-generation artists embraced Western Modernist art since the late 1970s and gradually mingled the two mainstreams into one at the end of the twentieth century.

The third dimension of my exploration concerns individual cases: artists of the 199 os tried to join the international contemporary art scene in the setting of globalization and localization, whereas the artists of the early twenty-first 
century ventured into domestic and international art markets, showcasing the commercial turn of contemporary art in the new era, which declared the death of the avant-gardism.

That being said, this study is an example of the so-called meta-art history due to its twofold purpose and may remind readers of Roland Barthes's (19151980) notion of 'utterance and utterance of that utterance' (Barthes 1972: 97) and his distinction between two types of texts, the readerly and the writerly, as well as his distinction between two types of writers, the écrivant and the écrivain. The former is a transitive writer and the latter is an intransitive writer who cares more about his or her writing in its own right (ibid: 147). However, my writing is more integral of the two types of texts and so my authorial identity in relation to this meta-art history writing is more integral of the two types of writer.

Needless to say, my writing involves narratological issues. Modern narratology was first developed in the field of literary study in the mid-twentieth century and later became a general approach to narrative, including art history. Inspired by and based on modern literary narratology and contemporary general narratology, my study outlines a narrative model and further constructs a narratological framework for the study of art history in the academic milieu of today. Thus, this authorial intention is self-consciously meta-art historical.

In the late 1970s and early 1980s, the Canadian literary scholar Linda Hutcheon (1947-) elaborated the narrative notion of metafiction from a postmodern point of view as self-referring or autorepresentational: 'it provides, within itself, a commentary on its own status as fiction and as language and also on its own process of production and reception' (Hutcheon 1985: xii). After the postmodern era, the notion of metanarrative developed in contemporary critical theories. British scholar Paul Cobley (1963-) introduced French linguist Emile Benveniste's (1902-1976) notion of metanarrative to narratology and distinguished two narrative levels. The first is the description of past events, without the involvement of the voice of the first person 'I', that is, the historian does not directly speak in his or her narrative. The second is a current discourse, in the present tense, which involves the first person (Cobley 2014: 185). In Cobley's two-level theory, the speaker 'I' takes part in the events of the narrative, which is a character in the story he or she tells, corresponding to an artist who tells the story of his or her involvement in a historical event of art. However, I wish to push the notion of the two-level metanarrative one step further and propose a third level for the narrative of art history. This is an integration of the past tense and the present tense in the reflexive and self-critical discourse on how to tell the story of art, involving the first-person voice 'I' in telling how to tell the story of art. 
Thus, the subject and approach are inseparable; they are bound to the fundamental question of this study: why Western influence and Chinese response? More than a half-century ago, the British historian Arnold J. Toynbee (18891975) faced a similar question about 'the unit of historical study' in writing his A Study of History: should a historical study be isolated? After a retrospective consideration of some key issues in the development of English history and the history of some other European nations, he concluded with a negative answer and pointed out that one nation's history is but a smaller part of a bigger history (Toynbee 1987: 3). According to Toynbee, the relationship of part-and-whole is mutually dependent and mutually decided, though there are spatial and temporal boundaries (ibid: $5^{-6}$ ). In the study of history and my narrative of modern Chinese art, this relationship is specified by the interaction between Western influence and Chinese response.

In this article, I intend to examine what has played the leading role in shaping Chinese art in modern times at every historical turning point and examine how it has defined the course of its development. Correspondingly, as the main thesis of my historical narrative, I propose that the 'what' and 'how' refer to Western influence and Chinese responses to that influence which are driven by the 'anxiety of cultural identity'.

\section{$2 \quad$ Anxiety of Cultural Identity}

Under the influence of the West, Chinese artists experienced an identity crisis that motivated them to respond to the influence.

An art historian is not only a storyteller but also an interpretive explorer with an analytical eye and a critical pen. Keeping this in mind, I wish to examine the complexities behind modern Chinese art. In order to do so, I focus on some key issues that are hidden deep, particularly, the Chinese anxiety towards Western dominance in the world of art and the narrative discourses of art history. It is in this regard that I make a point that the development of modern Chinese art is largely a history of Chinese responses to Western influence.

Scholars have offered various interpretations of the development of twentieth-century Chinese art and offered various theories about what has defined its progress throughout the past century. Art historians using a sociological approach regard the development of art as a part of social history, whereas those adopting the formalist approach regard it as a stylistic development. Interestingly, one art historian from Taiwan proposed a sociopolitical interpretation, claiming that it was Mao Zedong Thought that determined the development of Chinese art in the second half of the twentieth century 
(Lin 2002: 20). Although I do not completely oppose that interpretation, I propose a different one, which is my elaboration of the above-stated main thesis: in the early twentieth century, the interaction of Western influence and Chinese response caused the split of Chinese art into Western-style art and traditional-style art, forming two mainstreams that run side by side and also interwoven in the development of Chinese art in the rest of the twentieth century; then, towards the end of the century, contemporary Chinese art reached a point of confluence, gradually merging the two once-divided mainstreams into one in the early twenty-first century. This confluence is the latest development of Chinese art in modern times, and it is also its latest response to Western influence.

Certainly, Western art and art theory have cast a strong influence and thus defined the course of the development of Chinese art in modern times. However, behind this seemingly simple fact, there are some critical twists and complications, mainly in the ways in which Chinese artists and scholars have responded to the influence.

The interaction between Western influence and Chinese response is significant for my readers to gain insights into Chinese art in its economic, social, cultural, ideological, and political contexts. Therefore, investigating the key issues in this study, I address how Chinese artists and scholars have responded to Western influence. To elaborate my opinion, I refer to the Western critical concept of 'purposeful misreading', or 'intentional misreading' in literary studies. Why has such a misreading occurred in Chinese art? I offer the above notion of 'anxiety of identity' as an answer. The Chinese purposeful misreading is a crucial way to localize Western art forms and concepts in the globalized cultural setting. In other words, the purpose of the Chinese misreading is to construct its own contemporary art, which is also a way to search for and to construct, or reconstruct, its own cultural identity in the Western-dominated art world, and then cast its influence back. To be more specific, this is to convert Western art forms and concepts to Chinese and serve the purpose of advancing Chinese art and culture. On the other hand, this is also to internationalize Chinese art and culture as a political agenda to strengthen China's cultural presence in the international arena and to spread its global counter influence.

In terms of theoretical sources, in addition to some recent theories I find particularly inspiring, my discussion of 'anxiety of identity' is mainly informed by two great thinkers from the twentieth century: Toynbee and Harold Bloom (1930-2019).

Earlier, I mentioned Toynbee's theory about 'part and whole' in his study of history. In the same study, he proposed a theory of 'challenge and response' (Toynbee 1987:60) which supports his basic argument about the development 
of civilization. According to Toynbee, this development is a result of responses to certain challenges, and there are five or six types of challenges in the early development of civilization, which I simplify here into two: the environmental challenge and the human challenge. To my rewriting of the development of Chinese art in modern times, the second challenge is more relevant, and it is demonstrated in two respects: the external and the internal. The relation of challenges and responses is interactive. Regarding the challenge from Western civilization to others, Toynbee's opinion seems time-defying:

Is not this very challenge being actually presented under our eyes to the primitive inhabitants of Tropical Africa by the impact of our Western Civilization - a human agency which, in our generation, is playing the mythical role of Mephistopheles towards every other extant civilization and towards every extant primitive society on the face of the Earth? The challenge is still so recent that we cannot yet forecast the ultimate response that any of the challenged societies will make to it. We can only say that the failure of the fathers to respond to one challenge would not condemn the children to fail in face of another challenge when their hour came.

IBID: $72-73$

Then, regarding the response, Toynbee brings up a Chinese philosophical dichotomy, the interchangeable yin-yang relation, and the important concept of the hero, who is able to turn the passive yin-force into the active yang-force in responding to the challenge. In the case of early Chinese civilization, the hero belongs to the 'particular members' of the challenged civilization:

If certain members of that wide-spread race created a civilization while the rest remained culturally sterile, the explanation may be that a creative faculty, latent in all alike, was evoked in those particular members, and in those only, by the presentation of a challenge to which the rest did not happen to be exposed.

IBID: 74

Toynbee's hero who responded to the challenge reminds me of a similar personality in Bloom's literary theory, the 'strong poet'.

Bloom is one of the most influential Yale School critics of the 1980s and 1990 and is still considered a leading literary scholar in the early twenty-first century. In the 197os he developed a theory about literary influence in his study of the development of English poetry. According to Bloom, the poets from 
younger generations realize that they are the newcomers in the poetic world, and due to the shadow of the old masters, there is insufficient space for them to demonstrate their talents, the shadow makes them anxious. However, some young poets are 'strong poets'; they are creative and rebellious. They challenge the old masters by purposefully misreading and revising them.

For example, in Bloom's opinion, the anxiety of William Shakespeare (1564-1616) was to fight the shadow of another poet-dramatist of his time, Christopher Marlowe (1564-1593). Although Marlowe had a decisive influence on Shakespeare, as a strong poet Shakespeare eventually developed his own style through a purposeful misreading and revising of Marlowe's work and thus surpassed him. Interestingly, Bloom's theory of influence is influenced by the Freudian theory of the Oedipus complex, which partially comes from Sigmund Freud's (1856-1939) study of classical literature, especially Shakespeare, as well as from Freud's own battle against the Shakespearean shadow. Ironically or not, the Freudian concept of the Oedipus complex inspired and shadowed Bloom, just like Shakespeare's Hamlet inspired and shadowed Freud.

While Freud developed his psychoanalytic theory in the shadow of Shakespeare and Bloom developed his poetic theory in the shadow of Freud, I intend to link Bloom's theory of influence to my study by examining how Western influence created similar anxiety in Chinese artists as well as art historians and art critics, who then struggled towards establishing an independent identity and gaining an existential place and status in the world of art and art historical narrative. Intrinsic-Extrinsic Border

Regarding the methodology of critical theory in Western academia, generally speaking, the 196os is a historical watershed that differentiates the bordercrossing and extrinsic contextual study from the earlier formalist and intrinsic textual/visual study. At that time, Roland Barthes and his followers brought modern semiotics, along with modern narratology and image study (in Barthesian discourse, the term 'iconology' is somehow scarcely used), to the final stage of its development and almost reached the point of breaking down the intrinsic confinement.

Nonetheless, the breakthrough was achieved by Jacques Derrida (19302004) who deconstructed the autonomously confined modern semiotics and paved the way to postmodern and contemporary semiotics, which is open for 
almost limitless potentials and possibilities, theoretically. Then, what is contemporary semiotics? Due to its openness, there is no commonly accepted definition and elaboration. However, in terms of its fundamental difference from modern semiotics, I would say that while Barthes looked back and brought intrinsic structuralist semiotics to its near perfection and thus also to its end, Derrida looked ahead and opened up, willingly or not, an extrinsic world for its future development.

Regarding the extrinsic development thereafter, contemporary semiotics is certainly involved with its immediate predecessor, post-structuralist and/or postmodern semiotics, though they are different, temporally and conceptually. In the 1970s and 198os, postmodern is more deconstructive, subverting the modernist intrinsic doctrine. Then, from the 1980 os to the fin de siècle, contemporary is more reconstructive, developing some up-to-date extrinsic theories. In the field of art history, the link between postmodern and contemporary is the so-called 'New Art History', which is border-crossing, interdisciplinary, and integrative. In this study, border-crossing is contextual, referring to the extension of semiotic analysis to the contextual narrative.

It is in this consideration that I bring in the methodology of Mieke Bal (1946-), a renowned scholar of art history and comparative literature, as well as an artist and filmmaker, who has developed her semiotic and narrative reading of images into visual and cultural analyses. Bal regards narratology as a semiotic theory, and notes in her essay 'Interdisciplinary Narratology' that 'narrative itself, as a mode of communication, has specific semiotic features' and, since it can determine the production of meaning in semiotic interaction, 'narrative must be considered as a discursive mode which affects semiotic objects in variable degrees' (Bal 1994: 25). Integrating this general conception in her analytical reading of images, Bal makes her semiotic narrative more specific: 'narrative in visual art tend[s] to focus on the question of how images are able to narrate stories' (ibid: 194).

Bal's 'how' testifies to the main thesis of this study that the development of Chinese art in modern times tells the story of Western influence and Chinese responses. At this point, I wish to emphasize the significance of the contextual narrative, which lies in the fact that while I tell the contextual story of Chinese art, Chinese art also tells the story of its context, and the two are mutually dependent on each other. In other words, the contextual narrative provides a new perspective for image reading that is not intrinsically limited in meaning-making.

Regarding image reading and meaning-making in a contextual narrative, I must further refer to Bal: 
Trying to understand how images affect viewers in today's imagesaturated world, I have found semiotics helpful as a perspective, a set of conceptual tools, and a caution. As a perspective, it helps to consider a work of visual art as an object whose relevance derives from the processes in which it functions. Thus it takes art out of a formalist and autonomist idealization and takes the work as dynamic. Simultaneously semiotics also privileges meaning and the ways in which meaning is produced, considering aspects and details as signs rather than forms or material elements only.

BAL 1998: 74

Moreover, in Bal's reading of images, visual analysis is both synchronic and diachronic. With a strong sense of history, Bal developed her interdisciplinary semiotic approach beyond structuralism, from postmodern New Art History to contemporary visual cultural study. She first described her method as visual analysis, and then, with a political agenda, such as feminist ideological criticism, she further described it as cultural analysis. On the topic of historical sense in visual cultural study, at the very beginning of her introductory chapter in The Practice of Cultural Analysis: Exposing Interdisciplinary Interpretation, Bal elaborated on her conception:

Cultural analysis as a critical practice is different from what is commonly understood as 'history'. It is based on a keen awareness of the critic's situatedness in the present, the social and cultural present from which we look, and look back, at the objects that are always already of the past, objects that we take to define our present culture. Thus, it can be summarized by the phrase 'cultural memory in the present'. As such, it is immediately obvious that cultural analysis entertains an ambivalent relation to history as it is or has been traditionally practiced in our faculties. Far from being indifferent to history, cultural analysis problematizes history's silent assumptions in order to come to an understanding of the past that is different. This understanding is not based on an attempt to isolate and enshrine the past in an objectivist 'reconstruction', nor on an effort to project it on an evolutionist line not altogether left behind in current historical practice. Nor is it committed to a deceptive synchronism. Instead, cultural analysis seeks to understand the past as part of the present, as what we have around us, and without which no culture would be able to exist. 
Bal's historical sense stresses the importance of the present inclusiveness of the past and the mutual condition of the past and present, social and cultural. At this point, the historical sense is crucial. For my rewriting of the development of Chinese art in modern times, I indeed problematize the existing interpretations and give sound to the silent assumption about it. This sense also confirms my construction of the contextual narrative about the development of modern and contemporary Chinese art under Western influence.

With this sense, I can now turn from a general notion of semiotics to a more specific semiotic narrative, stressing the nature of border-crossing, or an interdisciplinary narrative. On this topic, 'narration' is the keyword related to another keyword, 'event'. Speaking from a semiotic point of view, a narration is a signifier whereas an event is the signified. However, Derrida subverted the signifying relationship of the two, and thus narration became problematic. Relevantly, speaking from a narratological point of view, Bal defined the event as such: 'An event is the transition from one state to another state'. She then elaborated: 'The word "transition" stresses the fact that an event is a process, an alteration' (Bal 2009: 6 and 189). Bringing Bal's notion of the event to my contextual narrative of Chinese art in modern times, I refer to the term 'event' as to what actually happened. In contrast, however, the narration is not the chain of events in art history, but a narration of the events, just like the image of a bed drawn by a painter in Plato's Republic. Bal briefly defined 'narration' as an 'act of creation' (ibid: 59) in the process of storytelling. In other words, while 'event' is what actually happened in art history, 'narration' is its subjective representation offered by an art historian or the narrator.

Due to the difference between event and narration, I dare to say that art historians of today have offered various narrations telling the story of modern Chinese art, but these are hardly sufficient or satisfactory; they tell us certain aspects of the story but leave gaps. In particular, they fail to take the interaction between Western influence and Chinese responses as a key aspect of the story. As said, a historical narration is not history itself but a narrative representation, which is thrice removed, or at least twice removed, from the truth, to borrow the words of Plato again (Plato 2000: 255). As mentioned, Lin proposed a sociopolitical and ideological narration, saying that it was Mao Zedong Thought that determined the development of modern Chinese art. Thereupon, this scholar almost touched on a key point but eventually missed it: Mao Zedong Thought is indeed a Chinese response to Western influence, the influence of Marxism. Mao embraced Marxism with revisions. In the terminology of today's cultural theory, it was Mao who localized Marxism for his pragmatic use in China. Although Lin grasped an important aspect of Chinese 
art in the second half of the twentieth century, I believe that Western influence and Chinese responses throughout the twentieth century should be taken as the main aspect. After all, Marxist influence in China is a part, or one aspect, of Western influence.

To construct my contextual narrative, I keep my border-crossing approach temporally 'being here' and 'being there' in the sense of New Historicism (Hamilton 1996: 153), and extend my discussion to a broader external context.

In my contextual narrative, while the term 'history' refers generally to social, political, and cultural history, it refers specifically to the history of art, and the integration of these different 'histories'. Indeed, relevant to the constant changes of historical conditions, the so-called 'historical sense' concerns at least four aspects of the condition. The first is the condition of the artist's time, which is the time when a certain work of art is created, or when a historical event takes place in the development of art. The second is the time referred to in artworks, such as the biblical time in a religious painting by a Renaissance artist. The third is the reader's time, which is the time when the work is read and interpreted. Consequently, the fourth is the reader's time of referent, or implied time, which is the time that the interpreter aims at when discussing the hidden message in a work of art. Importantly, it is the interactive relationship among the four aspects of the historical sense that makes the contextual narrative work.

The above narrative reinterpretation of the development of Chinese art in modern times comes from a narratological point of view. What is the difference between narrative and narratology? The former is an age-old literary term about storytelling, namely about what to tell and how to tell, while the second is a relatively new term of critical study, developed in the mid-twentiethcentury literary study but soon moving beyond it, becoming a study of general narrative. In my study, the notion of narratology is adopted from both literary and general narrative theories, which provides me with certain perspectives for the study of art history. While the notion 'narrative' is about both the stories told in works of art and the stories about art told by art historians, in this study, the notion 'narratology' is about the study of how art tells stories, how an artist tells a story in his or her artwork, and how an art historian tells the story about art, as well as how I retell the stories of art in different ways, and how I rewrite art history. 
A relatively new theory and methodology, narratology has its own developmental history, the pre-modern, modern, postmodern, and contemporary phases. The literary study of narrative in the pre-modern phase has a long history that can be traced back to Aristotle, and the origin of modern narrative study can be traced back to Russian formalist literary study in the early twentieth century. Then, modern narrative study enjoyed its triumph alongside structuralism in the mid-twentieth century. After that, especially since the poststructuralist era, the majority of narratologists followed the mainstream terminology, using the terms 'classical narratology' and 'post-classical narratology' (Herman 2007: 12) to differentiate formalist and contextualist theories of narrative. However, the two terms are confusing, since 'classical' might suggest 'pre-modern' and in fact formalist theory is very modern. In this case, temporality is less important, and conceptuality matters. In order to gain a historical and terminological coherence, I use the terms 'modern narratology' to refer to the formalist internal study demonstrated by Roland Barthes and his disciples, such as Gerard Genette (1930-2018) and Tzvetan Todorov (1939-2017), and use 'postmodern narratology' to refer to the succeeding external study. Nonetheless, I am not a formalist, though I am not an anti-formalist either. In my narratology for art history, I value both internal and external studies, and I use the term 'contemporary narratology' to refer to the integral theories and methods, which take the best from and mingle internal and external studies of the narrative.

What is internal, what is external, and what is integral? The internal study is confined within the text, while the external study is not. Referring to the topics in The Cambridge Companion to Narrative (2007), I consider that the notions of narration, time/space, character, dialogue, focalization, genre, and so forth are internal, and the notions of gender, ethics, ideology, cognition, identity, and so forth are external (ibid: v-vi). Then, how to integrate the two? Answering this question, I value the importance of context, which frames each of the internal notions and the external notions individually, while also framing all the internal and external notions together to form an entirety.

As for the notion of context, I consider both internal and external. The internal context is within the four borders of a piece of paper, on it a text is written or printed. Analogically, to the image of a human figure in a painting, the interior setting or the outdoor scene depicted in the painting is the internal context. On the contrary, the notion of external context concerns the background issues, such as historical setting, political environment, intellectual milieu, and so forth. To a painting, the connection or link between the two contexts is the frame, the frame in the sense of Bal and Derrida, though it also differs from their notions. 
I have worked on this research project lately, and my work is presented in full in my recent book Semiotics for Art History: Reinterpreting the Development of Chinese Landscape Painting (Newcastle 2019). In this book I outlined the following integrated model of visual communication:

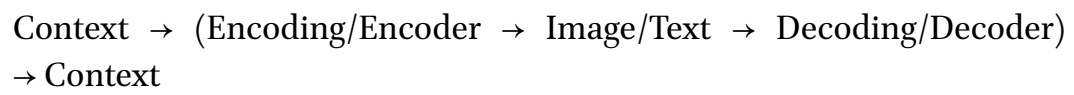

In this model, the integral function of context is clear. I then offered an elaboration:

Although this model looks common, it gives 'context' an essential role, which not only contextualizes each of the above three parts in parenthesis but also contextualizes the entire communication process as a whole. This whole is open, not closed. Meanwhile, this model also gives 'image/ text' the role of code, which exists at four levels for the decoder's further receptions and responses. Thus, with this model, I have at least four critical perspectives in interpreting artwork: context, artist/author, image/ text, and viewer/reader.

DUAN 2019: 231

Still, how does the integral context work exactly? In my perception, it works in a gradual process from the outside in. Now, in this article, I further integrate the internal and external studies by emphasizing two different perspectives within the parenthesis: first, the interaction between the encoder and the image, and second, the interaction between the decoder and the image. Then, I place the emphasis on the third perspective, the image, which is the connection of the other two opposite perspectives. Thus, I revise the above semiotic communication model and develop it into a narrative model for my rewriting of art history:

$$
\text { Context } \rightarrow(\text { Narrator/Author } \leftrightarrow \text { Image/Text } \leftrightarrow \text { Viewer/Reader }) \leftarrow \text { Context }
$$

Aside from redirecting the arrows, I also value the three perspectives in the terminology of narratological theory. The first is the interaction between author and text, or between the 'implied author' and 'possible world' of the image; the second is the interaction between reader and text, or between the 'implied reader' and the 'possible world'. The first leads to questioning and dismantling the existing narratives about modern Chinese art, and the second leads to focalizing my rewriting of the development of modern Chinese art on the issues of Western influence and Chinese response. 
Regarding the role of the author from the first perspective, while modern narratologists invented the notion of 'implied author', contemporary narratologists took a step further and distinguished 'model author' from 'empirical author'. Similarly, regarding the role of the reader from the second perspective, while modern narratologists invented the notion of 'implied reader', contemporary narratologists distinguished 'model reader' from 'empirical reader' (Eco 1995: 8).

Regarding the third perspective of the image that connects the author and reader, modern narratologists stressed intrinsicality, whereas contemporary narratologists emphasized extrinsicality. Needless to say, I must break down the boundary between the two, and go back and forth over the frame-border of an image. For this purpose, I discern three narrative layers in narrative writings about the image: external fabula, internal syuzhet (Zhao 2013: 119-142), and third-narration that crosses the external-internal border. Among the three, 'fabula' refers to the first-hand materials of art history, 'syuzhet' to the existing narratives about art, or the secondary story about the development of art, offered by other scholars and art historians in the past and present, and 'thirdnarration', or 'tertiary narrativization', to my reinterpretation of art history that is based on the first and second. In other words, the image/text in the centre of the model can be dealt with at three levels: the first-hand fabula, the secondary narration, and the tertiary narrativization.

Having laid out the model, I am now able to outline a narrative discourse for my rewriting of the development of Chinese art in modern times: from the first and second perspectives I present a contextually inclined integral narrative about the development of Chinese art in modern times, discussing more of the context; then, from the third perspective I present a textually inclined integral reinterpretation of the development, discussing more of the issues about the image. Congruously, I rename the above three corresponding notions 'firsthand fabula', which refers to the primary research data, 'secondary narration', which refers to other scholars' historical narratives about art, and 'tertiary narrativization', which refers to my own reinterpretation of the data and rewriting of art history.

In conclusion, the re-naming of these narrative terms is a part of my effort to theorize this specific study of modern Chinese art and incorporate them into a critical approach for the narrative study of art history in general. 


\section{References}

Bal, Mieke (2009) Narratology: Introduction to the Theory of Narrative (3rd ed). Toronto: University of Toronto Press.

Bal, Mieke, ed. (1999) The Practice of Cultural Analysis: Exposing Interdisciplinary Interpretation. Stanford, CA: Stanford University Press.

Bal, Mieke (1998) 'Seeing Signs: The Use of Semiotics for the Understanding of Visual Art', in Mark A. Cheetham et al. (eds.), The Subject of Art History: Historical Objects in Contemporary Perspective. Cambridge: Cambridge University Press.

Bal, Mieke (1994) On Meaning-Making: Essays in Semiotics. Sonoma, CA: Polebridge Press.

Barthes, Roland (1972) Critical Essays. Evanston, IL: Northwestern University Press.

Cobley, Paul (2014) Narrative. London: Routledge.

Duan, Lian (2019) Semiotics for Art History: Reinterpreting the Development of Chinese Landscape Painting. Newcastle: Cambridge Scholars Publishing.

Eco, Umberto (1995) Six Walks in the Fictional Woods. Cambridge, MA: Harvard University Press.

Hamilton, Paul (1996) Historicism. London: Routledge.

Herman, David, ed (2007) The Cambridge Companion to Narrative. Cambridge: Cambridge University Press.

Hutcheon, Linda (1985) Narcissistic Narrative: The Metafictional Paradox. New York and London: Methuen.

Lin, Xingyu (2002) History of One-Hundred-Year Chinese Oil Paintings: The Great Epic of Art in Twentieth Century (中国油画百年史, Zhongguo Youhua Bainian Shi). Taipei: Artists Publishing House.

Plato (2000) The Republic. Trans. Benjamin Jowett. New York: Dover Publications.

Toynbee, Arnold J (1987) A Study of History. Abridgement of Volumes I-VI by D. C. Somervell. New York: Oxford University Press.

Zhao, Yiheng (2013)A General Narratology (广义叙述学, Guangyi Xushuxue). Chengdu: Sichuan University Press. 